\title{
Organically Soluble Bifunctional Polyaniline-Magnetite Composites for Sensing and Supercapacitor Applications
}

\author{
S. Radhakrishnan, S. Prakash, Chepuri R. K. Rao, ${ }^{\mathrm{Z}}$ and M. Vijayan
}

Functional Materials Division, Central Electrochemical Research Institute, Karaikudi-630006, India

Soluble conducting polyaniline composites with low-level loadings of $\mathrm{Fe}_{3} \mathrm{O}_{4}$ have been synthesized and characterized. The composites are dispersible in many solvents including water and soluble in polar organic solvents, such as chloroform, $\mathrm{N}$-methylpyrrolidone, and methanol. The conductivity of the sample increases with increase in $\mathrm{Fe}_{3} \mathrm{O}_{4}$ loading and typically is in the range of $0.042-0.42 \mathrm{~S} / \mathrm{cm}$. The composites are bifunctionally useful in detecting dopamine electrochemically in the concentrations range 1-50 $\mu \mathrm{M}$ and also work as electrode materials for supercapacitor application. (C) 2009 The Electrochemical Society. [DOI: 10.1149/1.3074315] All rights reserved.

Manuscript submitted September 24, 2008; revised manuscript received December 31, 2008. Published January $29,2009$.

Conducting polymers (CPs) now own a special status in the field of electroactive materials, especially after the pioneering and noble prize winning work by Shirakawa et al. ${ }^{1}$ A great deal of progress has been made on these synthetic metals in terms of their synthesis, processability, and device applications. ${ }^{2-4}$ Particular attention on polyaniline (PAni) has been given due to its environmental stability, thin-film-forming property with tunable conductivity and commercial viability. Polyanilines have been studied extensively due to their applications to practical devices for energy storage, electrochemical sensors, electrochromic devices, electromagnetic interference shielding, and corrosion protection. ${ }^{3-10}$ Application of the CPs in energy storage devices is also well known, ${ }^{11}$ and recent studies ${ }^{12}$ in this area gave impetus to fundamental and applied research on CPbased materials. Recent literature ${ }^{13}$ identified the polyaniline composite materials as potential electrochemical sensors for various biomolecules.

Applications of conducting polymers are broadened by compositing with other inorganic materials. For example, polyaniline-metal nanoparticle composites exhibit enhanced sensing and catalytic properties, compared to pure polyaniline. ${ }^{14-19}$ Apart from the properties mentioned above, conducting polymers are useful as magneto/ electrorheological (ER) materials/fluids. ${ }^{20-23}$ ER fluids is a class of materials whose rheological characteristics are controllable through the application of an electric field. ER fluids are usually made of particle suspensions with a large dielectric constant mismatch between the particles and the fluid. Because of the controllable rheological properties, ER fluids can potentially be used as a smart material for active devices, which transform electric energy to mechanical energy. Polyaniline can change its property from a conducting to an insulating state using simple protonic acid treatment. This allows for a change in dielectric constant and conductivity of particles while keeping all other particle properties the same.

In the present communication, we report the synthesis of organically soluble bifunctional polyaniline-magnetite composites, which can sense dopamine and also act as supercapacitor electrode material. The results are presented and discussed.

\section{Experimental}

Materials and methods. - Analytical grade aniline monomer was purchased from Merck, India. Dodecylbenzene sulfonicacid (70 wt \% solution in 2-propanol) (DBSA) was purchased from Aldrich Chemical Company. Other characterization methods are similar to our earlier report. ${ }^{12}$

Synthesis of PAni-DBSA-Fe ${ }_{3} \mathrm{O}_{4}$ nanocomposites.- $\mathrm{Fe}_{3} \mathrm{O}_{4}$ magnetic particles were prepared by precipitation-oxidation method according to a known procedure, ${ }^{24}$ according to which the size of the magnetite particles are in the range of 20-30 nm. PAni-magnetite composites were prepared by an in situ polymerization of aniline

${ }^{\mathrm{z}}$ E-mail: ramchepuri@gmail.com
$(1 \mathrm{~mL})$ in DBSA (5 mL in $100 \mathrm{~mL}$ water) solution containing a specific amount of $\mathrm{Fe}_{3} \mathrm{O}_{4}$ magnetic particles according to the known procedure $^{25}$ with a slight modification. The main difference in the present synthesis is low loading of $\mathrm{Fe}_{3} \mathrm{O}_{4}$ material ranging from 0.2 to $0.8 \mathrm{~g}$ per $1 \mathrm{~mL}$ of aniline and using acid form of DBSA instead of salt form (Na-DBSA) in the known procedure. The polymerized products are designated as $\mathrm{C}-1, \mathrm{C}-2$, and $\mathrm{C}-3$ for $\mathrm{Fe}_{3} \mathrm{O}_{4}$ loadings of $0.2,0.4$, and $0.8 \mathrm{~g}$, respectively. On the basis of the yield of the final composite materials, the composites $\mathrm{C} 1-\mathrm{C} 3$ contain 7.7 , 19.7, and 33.6 wt $\%$ of $\mathrm{Fe}_{3} \mathrm{O}_{4}$, respectively. A control sample (PAniDBSA) was also prepared without addition of $\mathrm{Fe}_{3} \mathrm{O}_{4}$ particles and studied along with the composites for comparison.

\section{Results and Discussion}

Characterization.-Because of low-level incorporation of $\mathrm{Fe}_{3} \mathrm{O}_{4}$ particles and the surfactant nature of DBSA, the composites are soluble in chloroform and methanol, and dispersible in water. The solubility/dispersibility decreases with an increase in oxide incorporation. The characteristic Fourier transform IR (FTIR) peaks (Table I) of conducting polyaniline-DBSA, attributable to $\mathrm{C}=\mathrm{C}$ stretchings of benzenoid $(\mathrm{N}-\mathrm{B}-\mathrm{N})$ and quinoid $(\mathrm{N}=\mathrm{Q}=\mathrm{N}$ ) (where $\mathrm{B}=$ benzenoid and $\mathrm{Q}=$ quinoid) segments in the polymer chain are observed at 1558 and $1470 \mathrm{~cm}^{-1}$. The peak observed at $1296 \mathrm{~cm}^{-1}$ is assigned to the $\mathrm{C}-\mathrm{N}$ stretching vibration of the benzenoid ring. The band that fell in the range of $879 \mathrm{~cm}^{-1}$ is identified as the out-of-plane bending of $\mathrm{C}-\mathrm{H}$ bond in the 1,4-disubstituted ring. The peak at $\sim 1115 \mathrm{~cm}^{-1}$ is related to the poloron band formed by doping. The $\mathrm{R}-\mathrm{SO}_{3}^{-1}$ group of doped DBSA is seen at $1037 \mathrm{~cm}^{-1}$. The $\mathrm{C}-\mathrm{H}_{\mathrm{ar}}$ stretching is observed at $2922 \mathrm{~cm}^{-1}$. The composites also exhibit very similar IR bands. The main difference between iron oxide composites and pure PAni-DBSA is the decrease of NHstretching band intensity in former cases, which is possibly due to $-\mathrm{HN} \ldots \mathrm{Fe}_{3} \mathrm{O}_{4}$ interaction in the composites. The UV/visible spectrum of $\mathrm{C} 1$ in basic $N$-methylpyrrolidone solvent exhibited bands at 321,420 , and $601 \mathrm{~nm}$, suggesting that PAni is a partially doped state. Addition of $\mathrm{HCl}$ to this solution shifts electronic bands to $350 \mathrm{~nm}$ (assignable to $\pi \rightarrow \pi^{*}$ of benzenoid structures), $427 \mathrm{~nm}$ (excitations to poloron band), and $805 \mathrm{~nm}$ (excitations to poloron band).

$\mathrm{X}$-ray diffraction (XRD) studies on the composites revealed the inclusion of $\mathrm{Fe}_{3} \mathrm{O}_{4}$ particles in the composites. The profile exhibited peaks assignable to reflections due to (220), (311), (400), (422), (511), and (440) at $2 \Theta=30.16,35.49,43.12,53.55,57.05$, and 62.64 , respectively, due to $\mathrm{Fe}_{3} \mathrm{O}_{4}$ particles. ${ }^{26}$ Polyaniline matrix is amorphous and showed a broad hump centered at $2 \theta=20$ and a relatively sharper but still broad peak at $2 \theta=25.31$. The intensity of the peaks due to iron oxide increases upon increase of its loading in the composite from $\mathrm{C} 1$ to $\mathrm{C} 3$. The pristine polymer showed a conductivity of $0.5 \mathrm{~S} / \mathrm{cm}$ (Table I). The conductivity drops to nearly 1 order of magnitude $(0.048 \mathrm{~S} / \mathrm{cm})$ when $0.2 \mathrm{~g}$ of iron oxide is incorporated. This is possibly due to doping competition between iron 
Table I. Composition, conductivity, spectral, and specific capacitance data of the samples.

\begin{tabular}{|c|c|c|c|c|c|c|c|c|c|}
\hline \multirow{2}{*}{$\begin{array}{l}\text { Polymers/ } \\
\text { composites }\end{array}$} & \multicolumn{6}{|c|}{ FTIR $(\mathrm{KBr}$ pellet $)\left(\mathrm{cm}^{-1}\right)$} & \multirow[b]{2}{*}{$\begin{array}{l}\text { Conductivity } \\
(\mathrm{S} / \mathrm{cm})\end{array}$} & \multirow[b]{2}{*}{$\begin{array}{l}\text { Oxide content } \\
\quad(\text { wt } \%)\end{array}$} & \multirow[b]{2}{*}{$\begin{array}{l}\text { Sp. capacitance }(\mathrm{F} / \mathrm{g} \\
\left.\text { (at } 1 \mathrm{~mA} / \mathrm{cm}^{2}\right)\end{array}$} \\
\hline & $\mathrm{C}-\mathrm{H}_{\mathrm{op}}$ & $\mathrm{C}-\mathrm{N}_{(\mathrm{ar})}$ & $\mathrm{N}-\mathrm{B}-\mathrm{N}$ & $\mathrm{N}-\mathrm{Q}-\mathrm{N}$ & $\mathrm{CH}_{(\mathrm{ar})}$ & $\mathrm{N}-\mathrm{H}$ & & & \\
\hline PAni-DBSA & 792.8 & 1295 & 1470 & 1558 & 2922 & 3436 & 0.502 & - & 64 \\
\hline $\mathrm{C} 1$ & 794.2 & 1296 & 1474 & 1562 & 2916 & 3434 & 0.048 & $7.7 \%$ & 213 \\
\hline $\mathrm{C} 2$ & 793.6 & 1295 & 1469 & 1557 & 2920 & 3430 & 0.198 & $19.7 \%$ & 148 \\
\hline C3 & 792.9 & 1296 & 1461 & 1559 & 2922 & 3429 & 0.420 & $33.6 \%$ & 110 \\
\hline
\end{tabular}

oxide and DBSA; because of this, the doping percentage by DBSA greatly falls. Addition of further amounts of iron oxide $(0.4,0.8 \mathrm{~g})$ influenced in slow increment in the conductivity. The decrease in doping levels of DBSA is also reflected in nitrogen/sulfur (N/S) ratio. The N/S ratio is nearly 1 for pristine polymer and falls to 0.98 , 0.80 , and 0.73 with an increase in the concentration of iron oxide in the composites.

Electrochemical activity of the composites has been investigated. Figure 1 shows the cyclic voltammogram $(\mathrm{CV})$ of the composite on $\mathrm{Pt}$ foil electrode in $1 \mathrm{M}$ sulfuric acid. Two anodic oxidations of PAni take place at 0.271 and $0.751 \mathrm{~V}$ and reductions at 0.601 and $0.073 \mathrm{~V}$, suggesting the presence of conducting PAni; a middle oxidation peak generally observable for pure PAni between 0.3 and $0.4 \mathrm{~V}$ assignable to benzoquinone impurities/degradation products is absent and suggest that the composite is free of organic impurities. The plot of $v^{1 / 2}$ vs anodic peak current is linear (inset), and hence, the electron transfer is diffusion controlled. The parallelogram shape for the CV suggests that the material is useful for supercapacitor application.

Sensing of dopamine.- Dopamine (DA) is an important neurotransmitter and the loss of DA-containing neurons may lead to serious disease known as Parkinson's disease. The detection of DA has therefore been a subject of considerable interest in recent times in electroanalytical chemistry. It is well known that polyaniline and polypyrrole exhibits good electrochemical behavior and have been applied to the field of chemically modified electrodes for detection of biomolecules. ${ }^{12,27}$ It is also important to note that composites of $\mathrm{Fe}_{3} \mathrm{O}_{4}$ are also electrochemically active in sensing biomolecules. ${ }^{26}$ In view of this, in the present investigation, a glassy carbon electrode (GCE) has been modified by the composites $\mathrm{C} 1-\mathrm{C} 3$ by way of molecular self-assembly by dipping the GCE for $60 \mathrm{~s}$ in the composite solutions. These modified electrodes were used for sensing dopamine.

The cyclic voltammetric profile in Fig. 2 shows the oxidation of

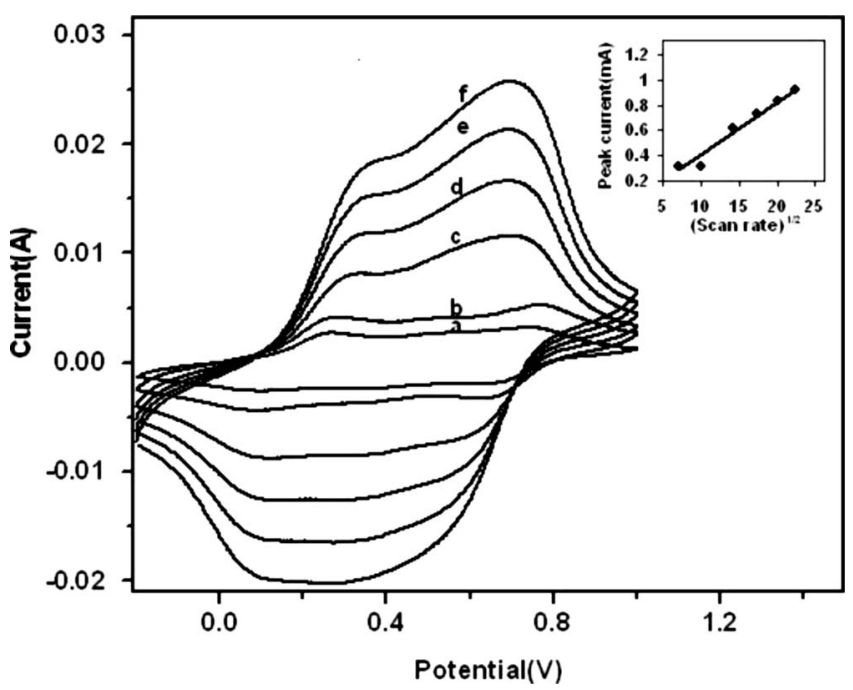

Figure 1. CV of composite $\mathrm{C} 1$ on Pt electrode at scan rates of $50-500 \mathrm{mV} / \mathrm{s}$ (a-f), respectively. various concentrations of dopaminehydrochloride using the modified electrode in $\mathrm{pH} 7.4$ for the representative composite $\mathrm{C}-1$. The oxidation peak in the presence of $1 \mu \mathrm{M}$ DA appears at 0.176 and is attributed to the oxidation of DA to dopaminequinone. ${ }^{28}$ There is a small reduction peak in the reverse scan at $-0.031 \mathrm{~V}$ attributable to partial reduction of dopaminequinone formed in the forward scan. When the concentration of dopamine to be sensed is increased to $50 \mu \mathrm{M}$, the oxidation potential slightly shifts to $0.200 \mathrm{~V}$. Pure PAni doped with DBSA did not show oxidation of dopamine. Other composites $\mathrm{C} 2$ and $\mathrm{C} 3$ with higher oxide loadings behaved similarly except that the reduction peak observed in the reverse scan is absent implying that it is sensitive to $\mathrm{Fe}_{3} \mathrm{O}_{4}$ loading. Thus, $\mathrm{C} 1$ is a better sensor material compared to the other composites.

Supercapacitance studies. - Very few reports are available on the use of $\mathrm{Fe}_{3} \mathrm{O}_{4}$ (or its composites) for supercapacitor applications. ${ }^{29,30}$ Pure $\mathrm{Fe}_{3} \mathrm{O}_{4}$ material ${ }^{29}$ showed a specific capacitance of 5-7 F/g, where as dispersion of this material on carbon black lead to high specific capacitance in the range $30-510 \mathrm{~F} / \mathrm{g}$. To the best of our knowledge, there is no report on the use of this material composited with PAni for the use of supercapacitor material. Hence, the pristine polymer and composites $\mathrm{C} 1-\mathrm{C} 3$ were tested for their supercapacitance properties. For this purpose, composite electrodes with stainless steel (SS) as current collectors $\left(1 \mathrm{~cm}^{2}\right)$ were prepared using poly(vinylidine fluoride) (10\%, Fluka) as binder and activated carbon (10\%, Fluka) as diluter and conductor. The electrodes were subjected to charge-discharge tests from 0.0 to $0.75 \mathrm{~V}$ in $1 \mathrm{M}$ sulfuric acid, and the specific capacitance (SC) values were calculated from discharge times using the formula $\mathrm{SC}=I t / 0.75 \mathrm{~m}$, where $I$ $=$ current density, $t=$ discharge time (in seconds), and $m=$ mass of the electroactive material.

It is clear from the data of Fig. 3 (Table I) that $\mathrm{C}-1$ exhibits highest $\mathrm{SC}$ of $213 \mathrm{~F} / \mathrm{g}$ at a current density $(\mathrm{cd})$ of $1 \mathrm{~mA} / \mathrm{cm}^{2}$. The

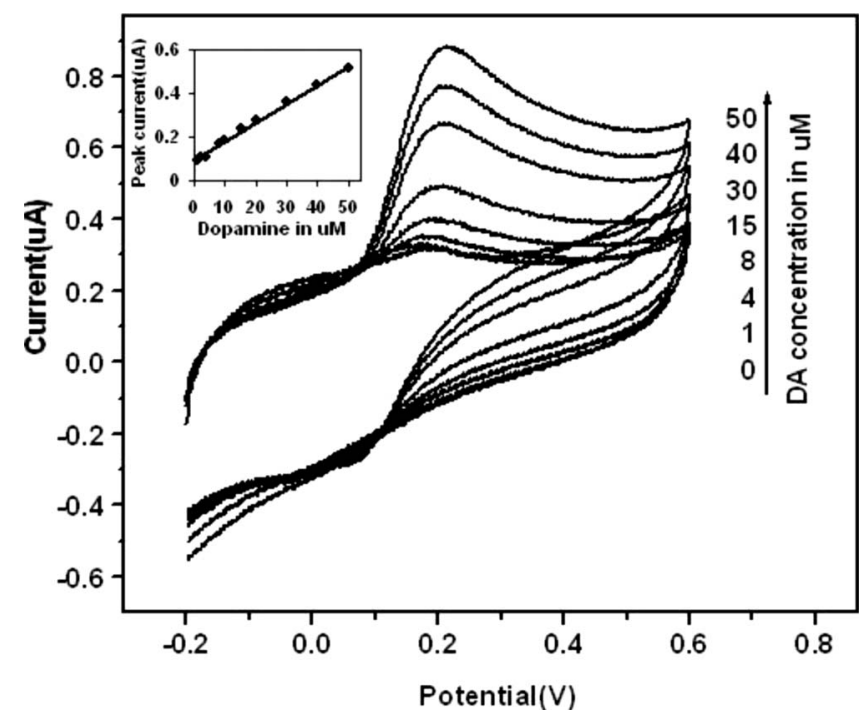

Figure 2. Dopamine oxidation at $\mathrm{C} 1-\mathrm{GC}$ electrode in $\mathrm{pH} 7.4$ buffer at $50 \mathrm{mV} / \mathrm{s}$ 


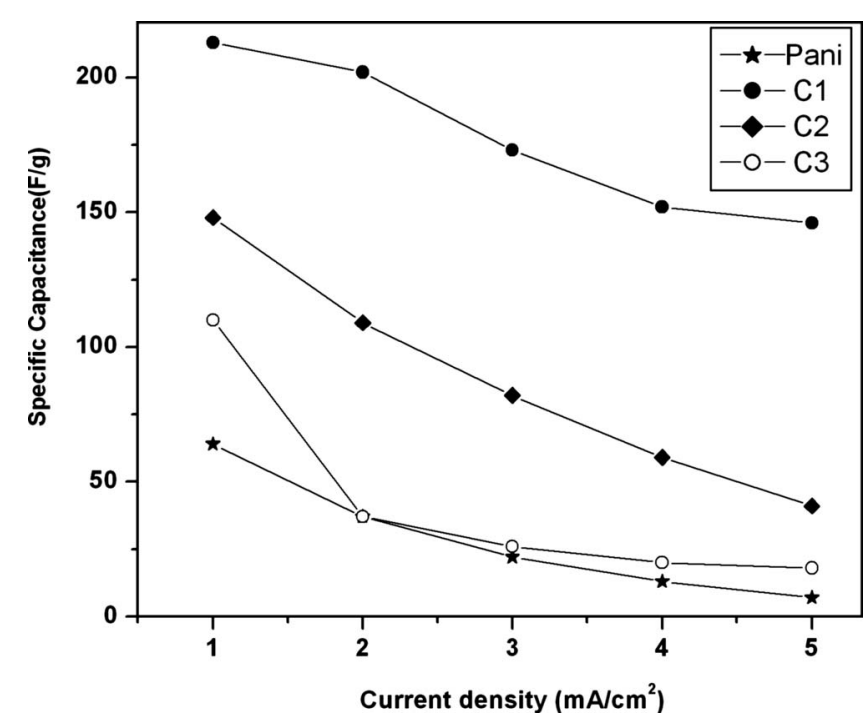

Figure 3. Specific capacitance (of first charge-discharge cycle) of Pani and its composites (deposited on SS) electrode as a function of current density.

value falls to $146 \mathrm{~F} / \mathrm{g}$ when cd is increased to $5 \mathrm{~mA} / \mathrm{cm}^{2}$. Composites $\mathrm{C} 2$ and $\mathrm{C} 3$ exhibited lower SC values of 148 and $110 \mathrm{~F} / \mathrm{g}$ at $1 \mathrm{~mA} / \mathrm{cm}^{2}$. These values still go down when cd is increased to $5 \mathrm{~mA} / \mathrm{cm}^{2}$ (Fig. 3). Pure PAni-DBSA showed an inferior SC value of $64 \mathrm{~F} / \mathrm{g}$ at $1 \mathrm{~mA} / \mathrm{cm}^{2}$. The composite $\mathrm{C} 1$ showed 3.3 times higher $\mathrm{SC}$ than the pristine polymer signifying the "synergistic effects" of the magnetite with polyaniline. The following mechanism seems to operate in the composite while charging and discharging

$$
\begin{aligned}
& \text { Charging: } \mathrm{PAni}+\mathrm{H}_{2} \mathrm{SO}_{4} \rightarrow\left[\mathrm{PAni}^{\circ} \cdot \mathrm{H}^{+}\right] \mathrm{HSO}_{4}^{-} \text {and } \\
& \mathrm{Fe}_{2} \mathrm{O}_{3} \cdot \mathrm{FeO} \rightarrow \mathrm{Fe}_{2} \mathrm{O}_{3} \cdot \mathrm{FeO}^{+}\left(\mathrm{HSO}_{4}^{-}\right)
\end{aligned}
$$

Discharging: $\quad\left[\mathrm{PAni} \cdot \mathrm{H}^{+\cdot}\right] \mathrm{HSO}_{4}^{-} \rightarrow \mathrm{PAni}+\mathrm{H}^{+}+\mathrm{HSO}_{4}^{-}$and

$$
\mathrm{Fe}_{2} \mathrm{O}_{3} \cdot \mathrm{FeO}^{+}\left(\mathrm{HSO}_{4}^{-}\right) \rightarrow \mathrm{Fe}_{2} \mathrm{O}_{3} \cdot \mathrm{FeO}+\mathrm{HSO}_{4}^{-}
$$

PAni undergoes oxidative doping in charging step and reductive dedoping in discharge step. There is no mechanism available in literature for the oxidation (charging) step when $\mathrm{Fe}_{3} \mathrm{O}_{4}$ is used as an electrode material. Here we propose that there is preferential oxidation of $\mathrm{Fe}$ (II) center in $\mathrm{Fe}_{2} \mathrm{O}_{3} \cdot \mathrm{FeO}$ to $\mathrm{Fe}$ (III) as shown above with intake of $\mathrm{HSO}_{4}^{-}$ions into the composite, which are expelled in the discharge step due to reduction of iron back to Fe(II). Thus, two faradaic oxidation reactions occur at one electrode surface while charging or discharging and are coupled together to enhance the SC synergistically.

The stability of the composite materials is verified up to 300 charge-discharge cycles, and the data are given for $\mathrm{C} 1$ at $5 \mathrm{~mA} / \mathrm{cm}^{2}$ (Fig. 4). Thus, it is observed that low loading of $\mathrm{Fe}_{3} \mathrm{O}_{4}$ into the polymer would benefit to increase the $\mathrm{SC}$ values as well as sensitivity in tracing low dopamine concentrations electrochemically. The detailed studies on supercapacitative properties of these composites, especially on the role and the redox mechanism of $\mathrm{Fe}_{3} \mathrm{O}_{4}$ and dopamine sensing with low incorporation of $\mathrm{Fe}_{3} \mathrm{O}_{4}$ are underway and will be published soon.

\section{Conclusions}

In this communication, we have developed procedures to synthesize soluble/dispersible polyaniline-magnetite composites. The composites showed bifunctional utility in detecting dopamine electrochemically in the concentrations range $1-50 \mu \mathrm{M}$ and also work as electrode materials for supercapacitor application with high specific capacitance values. The composite $\mathrm{Cl}$ allowed the use of higher

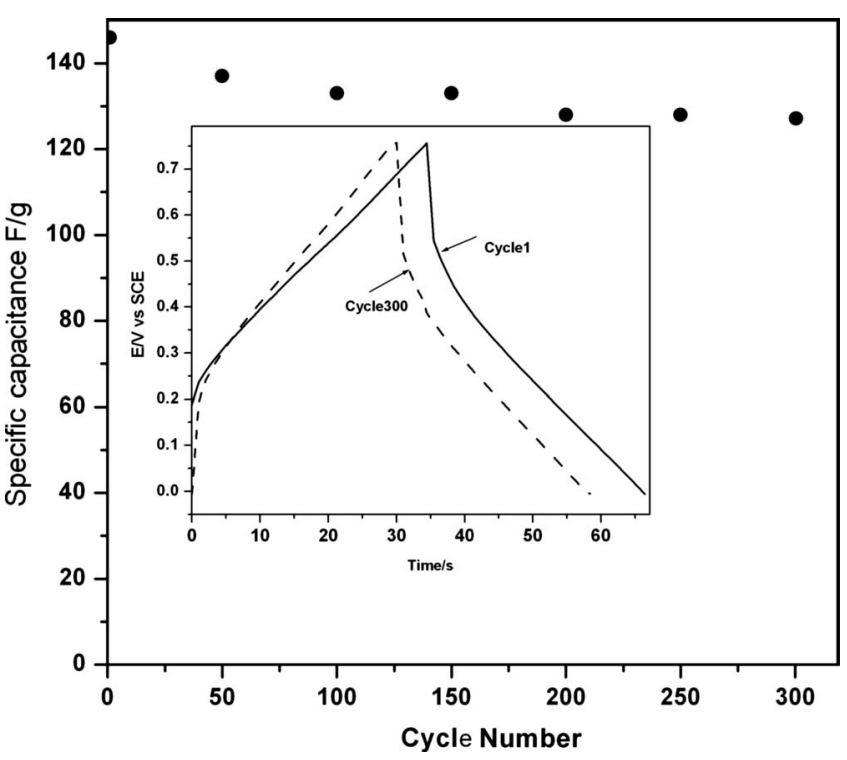

Figure 4. Variation of specific capacitance of $\mathrm{C} 1$ electrode with number of cycles at $5 \mathrm{~mA} / \mathrm{cm}^{2}$. Inset: Charge-discharge profile for $\mathrm{C} 1$.

current density between 1 and $5 \mathrm{~mA} / \mathrm{cm}^{2}$ for charge-discharge experiments. The present investigation also gives clues for fine tuning of bifunctional properties of the PAni-magnetite composites with low concentration of $\mathrm{Fe}_{3} \mathrm{O}_{4}$ particles.

\section{Acknowledgments}

The authors sincerely thank the director of CECRI for his constant encouragement, unstinted support, and for providing new sophisticated instrumental facilities without which the publication of this article would not be realized.

\section{References}

1. H. Shirakawa, L. J. Louis, A. G. McDiarmid, C. K. Chang, and A. J. Heeger, J. Chem. Soc., Chem. Commun., 1977, 578.

2. T. A. Skotheim, Editor, Handbook of Conducting Polymers, Vols. I and II, Marcel Dekker, New York (1986).

3. D. C. Trivedi, in Handbook of Organic Conductive Molecules and Polymers, Vol. 2, H. S. Nalwa, Editor, John Wiley \& Sons, Chichester (1997).

4. S.-M. Park, in Handbook of Organic Conductive Molecules and Polymers, Vol. 3 , H. S. Nalwa, Editor, John Wiley \& Sons, Chichester (1997).

5. A. Hugot-Le-Goff, in Handbook of Organic Conductive Molecules and Polymers, Vol. 3, H. S. Nalwa, Editor, John Wiley \& Sons, Chichester (1997).

6. A. Kitani, M. Kaya, and K. Sasaki, J. Electrochem. Soc., 133, 1069 (1986).

7. A. G. MacDiarmid, Synth. Met., 84, 27 (1997).

8. D. W. DeBerry, J. Electrochem. Soc., 132, 1022 (1985).

9. Y. Wang and X. Jing, Polym. Adv Technol, 16, 344 (2005).

10. A. Malinauskas, Synth. Met., 107, 75 (1999).

11. B. E. Conway, Electrochemical Supercapacitors-Scientific Fundamentals and Technology Applications, Kluwer Academic/Plenum, New York (1999).

12. M. Hughes, G. Z. Chen, M. S. P. Shaffer, D. J. Fray, and A. H. Windle, Chem Mater., 14, 1610 (2002); V. Gupta and N. Miura, Electrochem. Solid-State Lett., 8 A630 (2005); C. Peng, G. A. Snook, D. J. Fray, M. S. P. Shaffer, and G. Z. Chen, Chem. Commun. (Cambridge), 2006, 4629; S. Prakash, C. R. K. Rao, and M. Vijayan, Electrochim. Acta, 53, 5704 (2008).

13. D. W. Hatchett and M. Josowicz, Chem. Rev. (Washington, D.C.), 108, 746 (2008); A. Ramanavicius, A. Ramanaviciene, and A. Malinauskas, Electrochim. Acta, 51, 6025 (2006).

14. R. Gangopadhyay and A. De, Chem. Mater, 12, 608 (2000).

15. A. Kitani, T. Akashi, K. Sugimoto, and S. Ito, Synth. Met., 121, 1301 (2001).

16. A. Drelinkiewicz, M. Hasik, and M. Kloc, Catal. Lett., 64, 41 (2000).

17. Z. Q. Tian, Y. Z. Lian, J. Q. Wang, S. J. Wang, and W. H. Li, J. Electroanal. Chem. Interfacial Electrochem., 308, 357 (1991).

18. S. K. Pillalamarri, F. D. Blum, A. T. Tokuhiro, and M. F. Bertino, Chem. Mater, 17, 5941 (2005).

19. C. R. K. Rao and D. C. Trivedi, Catal. Commun., 7, 662 (2006).

20. J. H. Kim, F. F. Fang, H. J. Choi, and Y. Seo, Mater. Lett., 62, 2897 (2008).

21. Y. T. Lim, J. H. Park, and O. O. Park, J. Colloid Interface Sci., 245, 198 (2002).

22. J. W. Kim, S. G. Kim, H. J. Choi, and M. S. Jhon, Macromol. Rapid Commun., 20, 450 (1999) 
23. M. S. Cho, Y. H. Cho, H. J. Choi, and M. S. Jhon, Langmuir, 19, 5875 (2003).

24. X. B. Ding and G. X. Wan J. Appl. Polym. Sci., 79, 1847 (2001).

25. J. Deng, C. L. He, Y. Peng, J. Wang, X. Long, P. Li, A. S. C. Chan, Synth. Met, 139, 295 (2003)

26. Z. Liu, J. Wang, D. Xie, and G. Chen, Small, 4, 462 (2008).

27. A. Ramanavicius, A. Ramanaviciene, and A. Malinauskas, Electrochim. Acta, 51,
6025 (2006).

28. X.-Q. Lin and L. Zhang Anal. Lett., 34, 1585 (2001).

29. N.-L. Wu, S.-Y. Wang, C.-Y. Han, D.-S. Wu, and L.-R. Shiue, J. Power Sources, 113, 173 (2003).

30. N.-L. Wu, Mater. Chem. Phys., 75, 6 (2002). 